\title{
Implications of Kidney Disease in the Cardiac Patient
}

\author{
${ }_{\mathbf{Q} 2 \mathbf{Q}_{3} \text { Roger Rear }}^{\mathrm{a}, \mathrm{b}}$, Pascal Meier ${ }^{\mathrm{a}}$, Robert M. Bell ${ }^{\mathrm{a}, \mathrm{b}, *}$ \\ Q4Q5
}

8

\section{KEYWORDS}

- Cardiac $\bullet$ Cardiovascular disease $\bullet$ Chronic kidney disease $\bullet$ Chronic renal failure $\bullet$ Atrial fibrillation

- Coronary artery disease $\bullet$ Chronic heart failure

\section{KEY POINTS}

- Chronic kidney disease (CKD) is increasingly prevalent in patients with cardiovascular disease (CVD), and the 2 disease processes are closely interlinked by both etiology and pathophysiology.

- Cardiac patients with CKD may present atypically and have a considerably worse prognosis in all manifestations of CVD, as such, they warrant particularly vigilant specialist treatment.

- There is considerable evidence to support the use of most established cardiac interventions in patients with CKD, although many trials excluded patients with severe CKD and end-stage renal failure.

- Close monitoring of CKD patients is necessary during the treatment of cardiovascular disease to ensure safety and tolerability.

\section{INTRODUCTION}

Cardiovascular disease (CVD) and chronic kidney disease (CKD) are both encompassing terms that incorporate a spectrum of pathology that in the case of CVD includes arterial atherosclerosis, heart failure, diseases of the myocardium and pericardium, valvular disease, and cardiac arrhythmias. CKD in turn incorporates vascular, glomerular, tubulointerstitial, and obstructive nephropathies that result in a persistent (minimum of 3 months) depression of glomerular filtration rate (GFR) lower than 90 or, more typically, $60 \mathrm{~mL} / \mathrm{min} / 1.73 \mathrm{~m}^{2}$ (mild and moderate CKD, respectively) and/or the presence of albuminuria. The severity of CKD is classified into 5 categories, as defined by the National Kidney Foundation and the Kidney Disease Outcome Quality Initiative (Table 1). ${ }^{1}$ Despite the diversity of underlying abnormality in each pathologic condition, there appear to be several etiologic factors shared between CVD and CKD. The noninheritable, noninfectious CVDs typically incorporate "traditional" cardiovascular risk factors that include age, gender, hypertension, diabetes, dyslipidemia, smoking, and other lifestyle factors including obesity. Given that the most common forms of CKD share a significant number of these risk factors, particularly hypertension and diabetes (Fig. 1), ${ }^{2}$ it is unsurprising that a substantial proportion of cardiac patients also have significant renal impairment: approximately one-third of patients presenting for coronary angiography will have $\mathrm{CKD}^{3-5}$; in patients with heart failure the prevalence of CKD is estimated at between $32 \%$ and $53 \%$ (with the highest prevalence in those with acute decompensation $)^{6}$ and more than half of

The authors have nothing to disclose.

a The Heart Hospital, University College Hospitals NHS Trust, 16-18 Westmoreland Street, London, W1G 8PH, UK;

b The Hatter Cardiovascular Institute, University College London, 37 Chenies Mews, London, WC1E 6HX, UK

* Corresponding author. The Heart Hospital, University College Hospitals NHS Trust, 16-18 Westmoreland Street, London, W1G 8PH, UK.

E-mail address: rob.bell@ucl.ac.uk 
Table 1

Classification of chronic kidney disease according to estimated glomerular filtration rate (eGFR)

\begin{tabular}{llll} 
& eGFR (mL/min/1.73 $\left.\mathbf{~ m}^{\mathbf{2}}\right)$ & Renal Dysfunction & $\begin{array}{c}\text { 5-Year Mortality } \\
\text { (All-Cause) (\%) }\end{array}$ \\
\hline Stage I & $>90$ & With urine/imaging abnormality & - \\
\hline Stage II & $60-89$ & Mild & 20 \\
\hline Stage IIIa & $45-59$ & Moderate & 24 \\
\hline Stage IIIb & $34-44$ & Moderately severe & 24 \\
\hline Stage IV & $15-29$ & Severe & 46 \\
\hline Stage V & $<15$ & End stage, requiring RRT & 55 \\
\hline
\end{tabular}

Mortality data derived from Keith et al, ${ }^{1} 2004$ and US Renal Data System 2013 Annual Data Report. ${ }^{108}$

Abbreviation: RRT, renal replacement therapy.

patients with atrial fibrillation (AF) have $\mathrm{CKD},{ }^{7}$ increasing to nearly three-fourths of elderly AF patients ( $>80$ years) considered for anticoagulant therapy. ${ }^{8}$

By contrast, CVDs such as coronary artery disease and heart failure are highly prevalent in the CKD population, and increasingly so with deteriorating renal function: in severe CKD (stage IV), the prevalence of coronary artery disease (CAD) and heart failure reaches $19.0 \%$ and $12.5 \%$, respectively. ${ }^{1}$ Within this same patient cohort, the prevalence of hypertension and diabetes in individuals with CKD approaches $50 \%$ and $20 \%$, respectively. Significantly, these 2 comorbidities represent an increasing worldwide burden: in 2013, 1 billion people were treated for hypertension and 240 million patients for diabetes, with the totals projected to increase to an estimated 1.56 billion with hypertension by 2025 and 380 million with diabetes over the next decade. ${ }^{2}$ In these groups, the prevalence of CKD is $37 \%$ and $26 \%$, respectively, as reported by the US National Health and Nutrition Examination Surveys. ${ }^{9}$ The prevalence of CKD is therefore anticipated to increase significantly worldwide over the coming decades, and although there have been significant improvements in the rates of cardiovascular mortality (particularly with deaths related to CAD, which have fallen by approximately $50 \%$ over the last 3 decades $^{10}$ ), globally the pressure exerted by increasing prevalence of these comorbidities is contrary to the continuation of this positive trend.

CVD and CKD are intricately linked, and their prognoses interwoven. This review discusses how CKD affects common CVD prognosis, and the efficacy of and the adverse events arising from clinical cardiovascular interventions.

\section{CORONARY ARTERY DISEASE}

Atherosclerotic CAD is a prototypical example of the interaction between CKD and CVD. Mild renal dysfunction is increasingly recognized as a nontraditional cardiovascular risk factor for CAD: modest elevations of urinary albumin excretion below the current microalbuminemia diagnostic threshold erythematosus. 
are associated with elevated cardiovascular risk, ${ }^{11}$ which increases proportionately with progressive renal deterioration. ${ }^{12}$ Moreover, CKD, once established, doubles the rates of both CVD progres$\operatorname{sion}^{13}$ and in-hospital death following primary percutaneous intervention $(\mathrm{PCl})$ in comparison with those without CKD. ${ }^{14}$ The accelerated progression of CVD in CKD is likely to be multifactorial, incorporating several nontraditional risk factors that include hyperphosphatemia (and vascular calcification), ${ }^{15}$ oxidative stress and systemic inflammation, ${ }^{16}$ hyperhomocysteinemia, hypervolemia, mineral/electrolyte imbalance, anemia, ${ }^{17}$ thrombogenesis, and malnutrition. Consequently, in the CKD patient cohort, CVD mortality is not only 10 to 30 times higher than in the general population, ${ }^{1}$ but CVD is a also more likely adverse outcome than progressing to end-stage renal disease (ESRD) in these patients. ${ }^{18,19}$ Clinical management strategies therefore must center on the management of the underlying kidney disease and the common causes of hypertension and diabetes; there is emerging evidence that multidisciplinary approaches by nephrologists to control the progression of renal disease pays dividends in diminishing the rates of cardiovascular mortality in these patients. ${ }^{20}$

\section{Difficulties in Diagnosis of Acute Coronary Syndrome}

The existence of CKD frequently presents significant diagnostic challenges, not least in the diagnosis of patients presenting with chest pain. The electrocardiogram (ECG) frequently reveals nonspecific abnormalities, so the diagnosis of non-ST-elevation myocardial infarction, a more frequent presentation than ST-elevation myocardial infarction in CKD patients, ${ }^{21}$ requires further supportive diagnostic evidence. Patients with CKD frequently have elevated cardiac enzymes on routine testing, which make interpretation of absolute levels problematic, but a change of these cardiac enzymes over a period of 3 to 6 hours will be discriminatory for acute coronary syndrome (ACS). ${ }^{22}$ However, persistently elevated cardiac enzymes (such as troponin) should not be ignored in CKD: their elevation is an independent risk factor for cardiovascular mortality. ${ }^{23}$ The cause of a chronic troponin increase remains unclear, but is likely to represent myocardial injury potentially relating to microinfarction either secondary to epicardial CAD (53\% of patients with advanced CKD will have a coronary stenosis of greater than $50 \%$ in 1 or more coronary arteries ${ }^{24}$ ) or attributable to microvascular dysfunction/left ventricular hypertrophy, with data showing a strong correlation between left ventricular mass and serum troponin levels. ${ }^{25}$

Conversely, the diagnosis of ACS may be missed in patients with CAD and CKD, as the presentation is less likely to be with typical chest pain, ${ }^{26}$ potentially reflecting an underlying neuropathy: in the SWEDEHEART register, $67 \%$ of CKD patients with ACS had chest pain compared with $90 \%$ of those without CKD, and were more likely to present with heart failure. ${ }^{21}$ Moreover, more than half of patients referred for renal replacement therapy (RRT) are found to have clinically significant $\mathrm{CAD}$ in the absence of characteristic ischemic symptoms. ${ }^{24}$

Noninvasive screening methods for CAD can be used in patients with CKD. CKD patients are vulnerable to calcification of the intima-media of the coronary vessels. Cohort studies have demonstrated CKD to be an independent predictor of high computed tomography (CT) coronary artery calcium (CAC) scores in patients with clinically suspected $\mathrm{CAD},{ }^{27,28}$ and $\mathrm{CAC}$ scores correlate with the stage of renal dysfunction. ${ }^{29}$ Despite debate as to whether CT CAC scores correlate with luminal narrowing, CAC scores are validated as an independent predictor of future cardiac events, correlating with cardiac mortality in CKD patients. $^{30,31}$ However, the nephrotoxic risk of contrast exposure in CKD patients has meant that there has been little study of CT-coronary angiography in CKD. Of the other noninvasive screening methods, single-photon emission CT has variable and often low sensitivities in the CKD cohort of patients, and although dobutamine stress echo may be helpful in the screening of CAD, interpretation can prove difficult in the presence of left ventricular hypertrophy frequently found in CKD patients. ${ }^{32}$

Although the diagnosis of CAD in the CKD patient can be problematic, CKD patients have such a high burden of CAD that any cardiovascular presentation should be regarded with considerable suspicion and managed accordingly. ${ }^{26}$

\section{Medical Management of CAD in Patients with CKD}

Management of stable CAD consists of a combination of antiplatelet therapy, most commonly with the cyclooxygenase inhibitor aspirin, and aggressive traditional risk-factor management. The coexistence of CKD does not significantly alter this approach.

Aspirin remains beneficial in CKD patients with CAD: in patients with diastolic hypertension, the Hypertension Optimal Treatment (HOT) study found a significant reduction of cardiovascular 
events, particularly in those with more advanced CKD (IIlb) managed with $75 \mathrm{mg}$ aspirin, compared with control (reduction of major cardiovascular events by two-thirds, overall death reduced by half), with a nonstatistically significant trend toward higher bleeding rates (hazard ratio 2.81, $95 \%$ confidence interval $[\mathrm{Cl}] 0.92-8.84, P=.3$ in the CKD-IIlb group). ${ }^{33,34}$

Reduction of traditional cardiovascular risk factors, particularly hypertension and dyslipidemia, has the potential dual benefit of attenuating the progression of both CVD and CKD. Management of hypertension is well recognized and vital; current guidelines provide a target blood pressure of less than $140 / 90 \mathrm{~mm} \mathrm{Hg}$ in the general population, but is amended downward to $130 / 80 \mathrm{~mm} \mathrm{Hg}$ in those with CKD. ${ }^{35}$ The antihypertensive agents targeting the renin-angiotensin-aldosterone axis, specifically angiotensin-converting enzyme inhibitors (ACE-Is) and angiotensin II receptor blockers (ARBs), are discussed in greater detail in the relevant section herein.

Some controversy has surrounded the effectiveness of 3-hydroxy-3-methyl-glutaryl coenzyme A reductase inhibitors (the statins) in the context of CKD and CAD, but overall the data appear supportive of lipid-lowering agents being helpful in preventing the progression of cardiovascular, if not necessarily renal disease, in both subgroup analysis of existing cardiovascular trials ${ }^{4}$ and the prospective Study of Heart and Renal Protection (SHARP). ${ }^{36}$ Unfortunately, despite the evident benefit of statin therapy in mild to moderate CKD, statins are disappointingly ineffective in preventing death from CVD in dialysis-dependent end-stage CKD. ${ }^{37}$

$\beta$-Blockers for stable angina remain extremely useful in the symptomatic relief of angina symptoms in patients with CKD, but dose adjustments may need to be considered, particularly for the more hydrophilic agents (atenolol, bisoprolol; see later discussion).

In large part the medical management of CAD in patients with CKD is largely unaltered, and the targeting of cardiovascular risk factors benefits both CVD and CKD, with the possible exception of ESRD, in which the protective benefits of statin therapy on CVD seem to be lost.

\section{Implications of CKD and percutaneous coronary intervention}

Current interventional guidelines are clear in advocating that ACS management of patients with CKD should not differ from that of patients without. ${ }^{38}$ However, it should be recognized that patients with CKD have a worse short-term outcome and a higher adverse event rate, particularly in regard of major bleeding events, which are nearly double that in the non-CKD population (multivariate odds ratio $1.9,95 \% \mathrm{Cl} 1.22-2.96) .^{5,39}$ Great care needs to be invested, therefore, to ensure the use of appropriate doses of renal-excreted antithrombotic drugs, such as enoxaparin, fondaparinux, bivalirudin, and small-molecule glycoprotein IIb/IIla receptor blockers. In severe CKD these drugs may be contraindicated, and unfractionated heparin used in their place. ${ }^{38}$

A similar pragmatic approach is used in the management of stable CAD. In a post hoc analysis of the Clinical Outcomes Utilizing Revascularization and Aggressive Drug Evaluation (COURAGE) trial comparing outcomes of patients with CKD against those without, both patient groups had similar benefits with identical management strategies. Although PCl conferred no survival benefit in patients with $C K D,{ }^{40}$ there was no adverse signal with any combination of $\mathrm{PCl}$ and optimal medical therapy, suggesting that these patients should be managed in an individualized fashion comparable with that for non-CKD patients. ${ }^{41}$

In the management of both ACS and stable CAD, there needs to be cognizance of the problems associated with contrast-induced acute kidney injury (Cl-AKI). Although $\mathrm{Cl}-\mathrm{AKI}$ is frequently a short-term perturbation of creatinine clearance and is self-limiting, nearly one-fifth of patients may have persistent significant renal impairment ${ }^{3}$ and up to $9 \%$ will progress to ESRD and dialysis. ${ }^{42}$ Current guidelines recommend prehydration, cessation of nephrotoxic agents, and minimization of contrast load, ${ }^{43}$ with much current research interest in the potential beneficial roles of high-dose statin $^{44,45}$ and remote ischemic conditioning ${ }^{46,47}$ as renoprotective strategies during angiographic procedures.

\section{Implication of CKD and coronary artery bypass surgery}

Coronary artery bypass grafting (CABG) in patients with $\mathrm{CKD}$, as with $\mathrm{PCl}$, is associated with higher rates of adverse events, particularly for acute kidney injury (25\%-40\% increase in CKD-III and CKD-IV, respectively ${ }^{48}$ and bleeding events. ${ }^{49}$ However, in comparison with $\mathrm{PCl}$ in patients with complex, multivessel disease, CABG could be considered as an alternative revascularization strategy. In recent data from large cohort studies, CABG has better cardiovascular outcomes, with lower adjusted mortality, a lower rate of recurrent ACS, and a lower requirement for revascularization when compared with $\mathrm{PCl}{ }^{50,51}$ The presence of CKD may also influence decisions regarding the most appropriate surgical approach. In a cohort study of patients undergoing CABG, the off-pump 
CABG (OPCAB) group had statistically lower rates of in-hospital mortality and incident RRT in comparison with patients undergoing on-pump CABG (ONCAB), with the strongest effect seen with more advanced renal impairment: unadjusted incidence of mortality in patients with a reduced estimated GFR (eGFR; 15-29 and 30-59 mL/min/ $1.73 \mathrm{~m}^{2}$ ) was lowest among the OPCAB (vs ONCAB) cohort $(3.5 \%$ vs $5.2 \%$ and $2.2 \%$ vs $2.4 \%$, respectively), perhaps reflecting an injurious effect of cardiopulmonary bypass and the potential for transient organ hypoperfusion. ${ }^{52}$

Unfortunately there are no data available from large-scale, multicenter, randomized controlled trials to direct clinical management decisions regarding revascularization in high-risk patients with CKD, an area that would certainly benefit from further focused study given the particular problems presented by concomitant multivessel CAD and CKD.

\section{ATRIAL FIBRILLATION}

The Framingham Heart Study identified both valvular and nonvalvular risk factors for the development of $A F$, with significant differences between the genders: men had $50 \%$ greater AF prevalence than women, and women were significantly more likely than men to have a valvular etiology. It is recognized that calcific valvular disease is itself associated with CKD, particularly in dialysisrequiring ESRD. ${ }^{53}$ Interestingly the major nonvalvular risk factors for the development of $A F$, in addition to heart failure, are the traditional risk factors for cardiovascular disease, namely age, hypertension, and diabetes. ${ }^{54}$ Moreover, CKD is associated with the development of left ventricular hypertrophy, diastolic dysfunction, and subsequent left atrial dilatation, ${ }^{55}$ which increases the likelihood of developing AF. ${ }^{56}$ Given the riskfactor overlap between CKD and these recognized risk factors for $A F$, it is not surprising to discover that the prevalence of $A F$ within the CKD cohort of patients is high. In the Chronic Renal Insufficiency Cohort (CRIC) study, the prevalence of AF is 2 to 3 times greater in patients with CKD compared with the general population, with a prevalence of $16 \%$ with an eGFR 60 to $45 \mathrm{~mL} / \mathrm{min} /$ $1.73 \mathrm{~m}^{2}$ rising to more than $20 \%$ when the eGFR falls to less than $45 \mathrm{~mL} / \mathrm{min} / 1.73 \mathrm{~m}^{2}, 57$ compared with an estimate of $7.8 \%$ in the general population in the REGARDS study. ${ }^{58}$ However, whether CKD is a novel AF risk factor is unclear; the increased prevalence of $\mathrm{AF}$ within this population may be a simple expression of the presence of several common cardiovascular/renovascular risk factors (hypertension, aging, diabetes) leading to common root disorders such as arterial atherosclerosis, diastolic dysfunction, left ventricular hypertrophy, and heart failure, but the metabolic and electrolyte abnormalities associated with more advanced CKD may nonetheless be unique contributors toward the increased prevalence of $A F$ in the chronic renal impairment cohort. ${ }^{59}$

\section{Impact of CKD on AF Management}

In patients with persistent or permanent $A F$, in whom rate control is the preferred strategy, the use of drugs eliminated from the circulation by the kidney present a particular problem, no more so than for digoxin, which has a narrow therapeutic index and is largely (90\%) renally excreted. Indeed, digoxin therapy is associated with a $28 \%$ increased risk of death, associated predominantly with toxic digoxin levels and the presence of hypokalemia (a common electrolyte imbalance before dialysis). ${ }^{60}$ Other rate-control medications are also not entirely problem-free. $\beta$-Blockers as a class have varied excretion: hydrophilic agents such as atenolol and sotolol undergo renal elimination, and these drugs, like those with mixed metabolism such as bisoprolol, will require ECG monitoring and dose adjustments; the best rate-control options in CKD may therefore be lipophilic $\beta$-blockers such as metoprolol or carvedilol, or the use of a calciumchannel blocker such as diltiazem. ${ }^{61}$ Similarly, in pharmacologic rhythm control strategies, many of the preferred therapy options are limited by their dependence on renal excretion, including sotolol and flecainide (reviewed in Ref. ${ }^{61}$ ). However, both dronedarone and amiodarone are safe in patients with renal impairment.

Invasive interventions that can potentially cure the arrhythmia are feasible in the context of CKD, and the limitations to drug therapy imposed by CKD seems to make this approach more attractive. However, it should be noted that the success rate of $\mathrm{AF}$ ablation in the CKD population is somewhat lower than that found in the general population, with $\mathrm{AF}$ recurrence rates after ablation therapy typically $70 \%$ greater in CKD patients than in the general population, ${ }^{62,63}$ with both low eGFR and left atrial dilatation independently adversely influencing the success of catheter ablation. ${ }^{64}$ Therefore, the optimal approaches to the management of $A F$ in CKD patients require the weighing of individual risk factors and outcome benefits. However, as in other areas of CVD in the context of CKD, the main problem in making decisions regarding management of $A F$ in $C K D$ patients is the lack of data from prospective randomized controlled trials. 


\section{Impact of CKD on Anticoagulation}

Although the inclusion of CKD as a risk factor does not add to the power of the established predictive systemic embolization CHADSVASc ${ }^{65}$ risk-scoring system, ${ }^{66}$ CKD is nonetheless associated with a significant increase in the risk of thromboembolic stroke arising as a consequence of AF. ${ }^{67-69}$ Unfortunately, CKD is also associated with increased bleeding risk, and is recognized in scoring systems such as the HAS-BLED score (Hypertension, Abnormal liver/renal function, Stroke, Bleeding history/predisposition, Labile anticoagulation record, Elderly [>65 years], Drugs/alcohol coadministration/use). ${ }^{70}$ Warfarin undergoes hepatic metabolism using the cyp450 enzyme system, although Limdi and colleagues ${ }^{71}$ found that warfarin requirements were significantly lower in patients with CKD than in the general population (by $10 \%$ and $19 \%$ in moderate and severe CKD, respectively). Strict monitoring of the international normalized ratio in patients with CKD is therefore mandatory, and CKD patients without close scrutiny of anticoagulation record suffer high bleeding complication rates, particularly soon after initiation of oral anticoagulant therapy. ${ }^{72}$

There is, however, a general lack of strong data regarding the efficacy of warfarin and its ability to attenuate the rate of thromboembolic stroke in CKD patients, most data being retrospective and nonrandomized. ${ }^{69,72-75}$ Moreover, warfarin is associated with vascular calcification related to vitamin $\mathrm{K}$ antagonism, and there are reported risks of warfarin-related nephropathy. ${ }^{61}$ Despite this, current guidance continues to support the use of anticoagulation for thromboembolic risk reduction in the CKD cohort, which until recently has meant the administration and strict monitoring of warfarin. However, the increasing availability of novel oral anticoagulants will provide greater choice in the management of thromboembolic risk in patients with both $\mathrm{AF}$ and CKD. The antithrombin dabigatran ${ }^{76}$ and the factor-Xa inhibitors apixaban $^{77}$ and rivaroxaban ${ }^{78}$ all show at least noninferiority to warfarin anticoagulation in preventing thromboembolic stroke in mild and moderate CKD patients, with dabigatran and apixaban showing superior systemic embolism risk reduction and dabigatran lower rates of intracranial bleeding when compared with strictly monitored warfarin therapy. Although all 3 of the novel oral anticoagulants have at least an element of renal elimination (dabigatran is $80 \%$ renally excreted; the factor-Xa inhibitors less than one-third), all can be used with dose modifications in patients with mild and moderate CKD. None, however, have been trialed in patients with severe CKD and, consequently, only warfarin can be recommended at present for use in patients with an eGFR of less than $15 \mathrm{~mL} / \mathrm{min} / 1.73 \mathrm{~m}^{2}$.

\section{CHRONIC HEART FAILURE}

Chronic heart failure (CHF) is a complex clinical syndrome resulting from the inability of the heart to maintain adequate tissue perfusion, because of either structural or functional abnormalities affecting the systolic and/or diastolic phase of the cardiac cycle. CKD is highly prevalent in the CHF patient cohort and, despite the usual exclusion of patients with severe CKD, this is reflected in the landmark heart failure trial literature, with prevalence rates estimated between $32 \%$ and $50 \%$ (Table 2). CKD adversely affects the prognosis of CHF: a recent meta-analysis of $85 \mathrm{CHF}$ trials (comprising 49,890 patients) revealed a doubling of all-cause mortality within this patient population (Table 3$)^{6}$

The link between CHF and CKD is in part attributable to shared etiologic risk factors, but is also a direct consequence of the interaction of their respective pathophysiology (Fig. 2). For example, low cardiac output and increased venous congestion (predominant in heart failure with preserved ejection fraction) respectively reduce renal arterial blood flow and perfusion gradient, ${ }^{79}$ exacerbating kidney dysfunction, which can be further

mated glomerular filtration rate; N/A, no data available. 
Table 3

All-cause mortality based on severity of CKD

\begin{tabular}{lllll} 
& $\begin{array}{l}\text { All CKD } \\
\text { 32\% Prevalence }\end{array}$ & Moderate CKD & Severe CKD & WRF \\
\hline All-cause mortality & $2.34 \mathrm{OR}$ & $1.59 \mathrm{HR}$ & $2.17 \mathrm{HR}$ & $1.81 \mathrm{OR}$ \\
& $95 \% \mathrm{Cl} 2.2-2.5$ & $95 \% \mathrm{Cl} 1.49-1.69$ & $95 \% \mathrm{Cl} 1.95-2.40$ & $95 \% \mathrm{Cl} 1.55-2.12$ \\
& $P<.001$ & $P<.001$ & $P<.001$ & $P<.001$
\end{tabular}

Abbreviations: $\mathrm{Cl}$, confidence interval; $\mathrm{CKD}$, chronic kidney disease; HR, hazard ratio; OR, odds ratio; WRF, worsening renal function.

Data from Damman K, Valente MA, Voors AA, et al. Renal impairment, worsening renal function, and outcome in patients with heart failure: an updated meta-analysis. Eur Heart J 2014;35(7):455-69.

aggravated by the therapies used to manage $\mathrm{CHF}$, through any combination of diuresis-associated hypovolemia, renin-angiotensin-aldosterone system (RAAS) inhibitors, and drug-induced hypotension. By contrast, renal dysfunction leads to neurohormonal dysregulation, anemia, volume overload, and complex inflammatory cascades that negatively affect cardiac function. The bidirectional interaction between 2 failing organ systems can lead to a vicious cycle of progressive cardiac and renal dysfunction, termed cardiorenal syndrome, the classifications of which are summarized in Table $4 .{ }^{80}$

\section{Medical Management of CHF in Patients with CKD}

The established canon of CHF management consists of ACE-Is/ARBs, $\beta$-blockers, and mineralocorticoid receptor antagonists (MRAs), with 2 decades of landmark mortality outcome data to support their use (Table 5). In patients with normal renal function, all improve prognosis, reduce hospitalizations, and improve mortality rates. The coexistence of CKD, however, introduces particular challenges for the introduction and maintenance of CHF therapy.

Perhaps the most innocuous of these drug classes are the $\beta$-blockers. $\beta$-Blockers have no adverse impact on the progression of CKD, and the efficacy of $\beta$-blockade in CHF seems unaltered by the existence of CKD: a retrospective analysis of outcomes in the CIBIS-II study reported preserved relative risk reduction in patients treated with bisoprolol at all stages of CKD, ${ }^{81}$ data supported from observations in the MERIT-HF trial. ${ }^{82}$ As discussed earlier, individual $\beta$-blockers have variable dependence on renal elimination: hydrophilic drugs (atenolol and bisoprolol) will require dose adjustments and monitoring in CKD, whereas the lipophilic $\beta$-blockers (carvedilol and metoprolol), which undergo hepatic metabolism, do not, ${ }^{83}$ an observation that may help influence the optimal choice of therapeutic agent.

By contrast, drugs that affect the RAAS axis require greater caution when $\mathrm{CHF}$ coexists with CKD. The ACE-Is/ARBs are a prototypical example of this. In addition to their role in the management of CHF, ACE-Is and ARBs are also pivotal to the management of CKD, attenuating progression of hypertensive, proteinuric $\mathrm{CKD}^{84}$ and lower mortality rates, as suggested by retrospective population studies. ${ }^{85}$ However ACE-Is/ARBs are not innocuous in terms of renal function: a modest perturbation of GFR is frequently found following ACE-I or ARB initiation, with an increase of creatinine to a new 10 - to $20-\mu \mathrm{mol} / \mathrm{L}$ higher baseline observed in the CONSENSUS study. ${ }^{86}$ However, although CHF studies excluded patients with severe CKD,

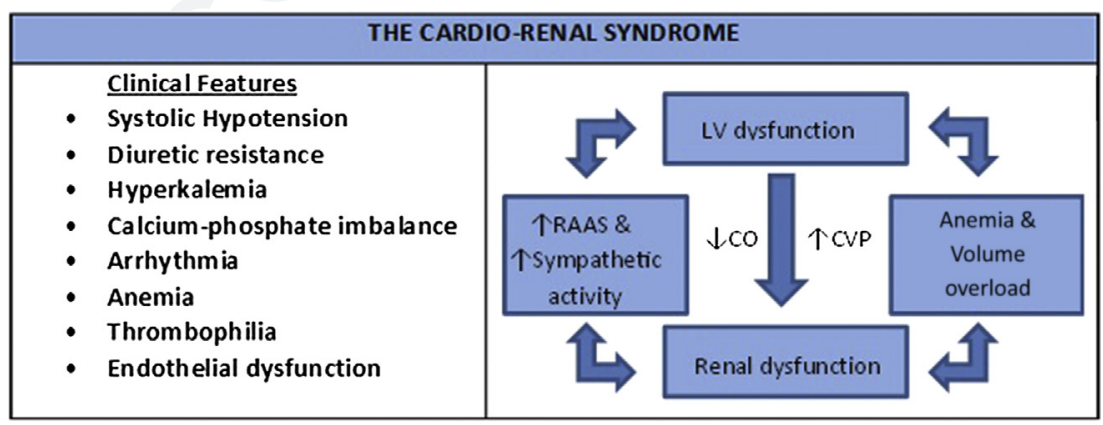

Fig. 2. The cardiorenal syndrome: clinical features and pathophysiologic mechanism. CO, cardiac output; CVP, central venous pressure; LV, left ventricle; RAAS, renin-angiotensin-aldosterone system. 
in patients with mild and moderate CKD the cardiovascular mortality benefit of ACE-Is/ARBs appears to be preserved. ${ }^{87-89}$

With respect to the MRAs, both the RALES ${ }^{90}$ and EMPHASIS-HF studies ${ }^{91}$ (in which half and a third of patients had CKD, respectively) demonstrated mortality reductions (30\% and $34 \%$, respectively), in addition to reduced symptoms and hospitalizations. Both trials excluded patients with severe CKD (RALES used a cutoff of $221 \mathrm{mmol} / \mathrm{L}$; EMPHASIS-HF an eGFR of $30 \mathrm{~mL} / \mathrm{min} / 1.73 \mathrm{~m}^{2}$ ), but MRAs remain effective therapies in CHF when there is coexistent mild to moderate CKD. ${ }^{92}$ Unfortunately, the use of aldosterone antagonists in patients with severe CKD can provoke hyperkalemia, especially in conjunction with ACE-ls or ARBs. Current European guidelines recommend that a serum creatinine level higher than $220 \mu \mathrm{mol} / \mathrm{L}$ or potassium level higher than $5 \mathrm{mmol} / \mathrm{L}$ is a contraindication, although cautious use is usually well tolerated in mild or moderate CKD. ${ }^{93}$

Excessive sodium and water retention is usually present in CHF patients with CKD, and should be treated initially with dietary sodium restriction ( $<2 \mathrm{~g}$ salt/d), but may require intensive diuretic therapy using the minimum dose required to achieve a "dry weight"; diuretic overdosing is associated with increased mortality. ${ }^{94}$ Loop diuretics are more effective than thiazide diuretics, and, if necessary, cautious combination of both agents may be used. ${ }^{95}$ However, unlike the MRA class of diuretics, there is no prognostic benefit to be derived from loop or thiazide diuretics in the setting of either CHF or CKD.

\section{Management of Anemia}

Anemia is a significant problem in patients with $\mathrm{CHF}$ and CKD, and often remains overlooked in busy specialist clinics. ${ }^{96} \mathrm{CHF}$ mortality increases with severity of anemia by $50 \%$ to $100 \%{ }^{97}$ and the presence of CKD further doubles the mortality. ${ }^{98}$ Current European guidelines recommend correcting hemoglobin levels to between 10 and $12 \mathrm{~g} / \mathrm{dL}$; however, recent systematic reviews and meta-analyses have shown worse outcomes when levels are normalized (>13 g/dL). ${ }^{99,100}$ Initial correction of iron deficiency with oral or parenteral iron before low-dose erythropoietin-stimulating agents are recommended to minimize the need for blood transfusions.

\section{Device Therapy}

Post hoc subanalysis of CARE-HF ${ }^{101}$ showed that the relative effect of cardiac resynchronization therapy (CRT) was similar among eGFR subgroups, whereas subanalysis of the MIRACLE study demonstrated an improvement in baseline 
Table 5

Summary of the major CHF trials with CKD subgroup analysis data

\begin{tabular}{|c|c|c|c|c|c|}
\hline Trial Name & $\begin{array}{l}\text { Treatment/Target } \\
\text { (Mean Daily Dose) }\end{array}$ & Outcome & Effect (\%) & $\begin{array}{l}\text { CKD I-III } \\
\text { Effect }\end{array}$ & CKD IV-V Effect \\
\hline CONSENSUS ${ }^{112}$ & $\begin{array}{l}\text { Enalapril } 20 \mathrm{mg} \text { bid } \\
\quad(18.4 \mathrm{mg})\end{array}$ & $\begin{array}{c}1^{\circ}: \text { All-cause } \\
\text { mortality }\end{array}$ & $\begin{array}{l}\text { RRR 27, } \\
\quad \text { ARR } 15\end{array}$ & Preserved & $\begin{array}{l}\text { Preserved (NS) } \\
<30 \mathrm{~mL} / \mathrm{min} / \\
1.73 \mathrm{~m}^{2}\end{array}$ \\
\hline SOLVD $^{109}$ & $\begin{array}{l}\text { Enalapril } 10 \mathrm{mg} \text { bid } \\
\quad(16.6 \mathrm{mg})\end{array}$ & $\begin{array}{c}1^{\circ}: \text { All-cause } \\
\text { mortality }\end{array}$ & RRR 16 & Preserved & $\begin{array}{l}\text { Preserved } \\
<45 \mathrm{~mL} / \mathrm{min} / \\
1.73 \mathrm{~m}^{2} \\
\end{array}$ \\
\hline CHARM-ALT ${ }^{110}$ & $\begin{array}{l}\text { Candesartan } 32 \mathrm{mg} \\
\text { qd (23 mg) }\end{array}$ & $\begin{array}{c}1^{\circ}: \text { CV mortality + } \\
\text { HF admission }\end{array}$ & RRR 23, AR 7 & Preserved & No data \\
\hline MERIT-HF ${ }^{113}$ & $\begin{array}{l}\text { Metoprolol } 200 \mathrm{mg} \\
\text { qd (159 mg) }\end{array}$ & $\begin{array}{c}1^{\circ}: \text { All-cause } \\
\text { mortality }\end{array}$ & $\begin{array}{l}\text { RRR 34, } \\
\text { ARR } 3.8\end{array}$ & Preserved & $\begin{array}{l}\text { Preserved } \\
<45 \mathrm{~mL} / \mathrm{min} / \\
1.73 \mathrm{~m}^{2}\end{array}$ \\
\hline CIBIS-II ${ }^{114}$ & $\begin{array}{l}\text { Bisoprolol } 10 \mathrm{mg} \text { qd } \\
\quad(8.6 \mathrm{mg})\end{array}$ & $\begin{array}{c}1^{\circ}: \text { All-cause } \\
\text { mortality }\end{array}$ & $\begin{array}{l}\text { RRR 32, } \\
\text { ARR } 5.5\end{array}$ & Preserved & $\begin{array}{l}\text { Preserved } \\
<45 \mathrm{~mL} / \mathrm{min} / \\
1.73 \mathrm{~m}^{2}\end{array}$ \\
\hline $\begin{array}{l}\text { COPERNICUS }{ }^{115} \\
\text { CAPRICORN }^{116}\end{array}$ & $\begin{array}{l}\text { Carvedilol } 25 \mathrm{mg} \\
\text { bid (37 mg) }\end{array}$ & $\begin{array}{c}1^{\circ}: \text { All-cause } \\
\text { mortality }\end{array}$ & $\begin{array}{l}\text { RRR 35, } \\
\text { ARR } 5.6\end{array}$ & Preserved & $\begin{array}{l}\text { Preserved } \\
<45 \mathrm{~mL} / \mathrm{min} / \\
1.73 \mathrm{~m}^{2}\end{array}$ \\
\hline RALES $^{90}$ & $\begin{array}{l}\text { Spironolactone } \\
50 \mathrm{mg} \text { qd }(26 \mathrm{mg})\end{array}$ & $\begin{array}{c}1^{\circ}: \text { All-cause } \\
\text { mortality }\end{array}$ & $\begin{array}{r}\text { RRR 30, } \\
\text { ARR } 11 \\
\end{array}$ & Preserved & $\overline{\text { Contraindicated }}$ \\
\hline EMPHASIS-HF ${ }^{91}$ & $\begin{array}{c}\text { Eplerenone } 50 \mathrm{mg} \\
\text { qd }(39.1 \mathrm{mg}), \\
25 \mathrm{mg} \text { CKD III }\end{array}$ & $\begin{array}{c}1^{\circ}: \text { CV mortality }+ \\
\text { HF admission }\end{array}$ & $\begin{array}{l}\text { RRR 34, } \\
\text { ARR } 7.6\end{array}$ & Preserved & Contraindicated \\
\hline $\mathrm{DIG}^{117}$ & $\begin{array}{l}\text { Digoxin variable } \\
(0.25 \mathrm{mg})\end{array}$ & $2^{\circ}: \mathrm{HF}$ admission & $\begin{array}{r}\text { RRR 28, } \\
\text { ARR } 7.9 \\
\end{array}$ & Preserved & Preserved \\
\hline SHIFT $^{118}$ & $\begin{array}{l}\text { Ivabradine } 7.5 \mathrm{mg} \\
\text { bid }(6.5 \mathrm{mg})\end{array}$ & $\begin{array}{c}1^{\circ}: \text { CV mortality+ } \\
\text { HF admission }\end{array}$ & $\begin{array}{r}\text { RRR 18, } \\
\text { ARR } 5 \\
\end{array}$ & No data & No data \\
\hline A-HEFT' 119 & $\begin{array}{l}\text { Hydralazine/ISDN } \\
75 \mathrm{mg} / 40 \mathrm{mg} \text { tid } \\
(142.5 \mathrm{mg} / 76 \mathrm{mg})\end{array}$ & $\begin{array}{l}1^{\circ}: \text { All-cause } \\
\text { mortality }^{\mathrm{a}}+\mathrm{HF} \\
\text { admission }^{\mathrm{b}}+ \\
\mathrm{QOL}\end{array}$ & $\begin{array}{r}\text { RRR } 43^{\mathrm{a}} / 33^{\mathrm{b}} \\
\text { ARR } 4.0^{\mathrm{a}} / 8^{\mathrm{b}}\end{array}$ & No data & No data \\
\hline MADIT II ${ }^{120}$ & ICD & $\begin{array}{c}1^{\circ}: \text { All-cause } \\
\text { mortality }\end{array}$ & $\begin{array}{l}\text { RRR 31, } \\
\text { ARR } 5.6 \\
\end{array}$ & Preserved & Preserved (NS) \\
\hline CARE-HF $^{111}$ & CRT & $\begin{array}{c}1^{\circ}: \text { CV mortality }+ \\
\text { CV admission }\end{array}$ & $\begin{array}{r}\text { RRR } 37 \\
\text { ARR } 16 \\
\end{array}$ & Preserved & No data \\
\hline MADIT-CRT ${ }^{121}$ & CRT-D & $\begin{array}{l}1^{\circ}: \text { All-cause } \\
\text { mortality + HF } \\
\text { admission }\end{array}$ & $\begin{array}{r}\text { RRR } 17.2 \\
\text { ARR } 8.1\end{array}$ & Preserved & No data \\
\hline
\end{tabular}

Abbreviations: ARR, absolute risk reduction; bid, twice daily; CRT, cardiac resynchronization therapy; CRT-D, cardiac resynchronization therapy with defibrillation; CV, cardiovascular; HF, heart failure; ICD, implantable cardioverterdefibrillator; ISDN, isosorbide dinitrate; NS, not significant; qd, once daily; QOL, quality of life score; RRR, relative risk reduction; tid, 3 times daily.

renal function. ${ }^{102}$ However, another subanalysis of the REVERSE study ${ }^{103}$ found that CKD patients treated with CRT had worse left ventricular parameter outcomes, which the investigators attributed to CKD-specific impairment of reverse left ventricular remodeling. For patients who might reasonably be expected to proceed to dialysis, consideration of the site of arteriovenous fistula before device implantation is recommended to avoid complications secondary to pacing wireassociated central venous stenosis. ${ }^{104}$

Patients with CKD have a significantly increased risk of sudden cardiac death (SCD) from ventricular arrhythmia, particularly so during dialysis, and limited evidence suggests they should be offered implantable cardioverter-defibrillator (ICD) therapy if they meet the usual criteria ${ }^{105}$; however, concerns exist regarding the efficacy of ICDs in 
ESRD. ${ }^{106}$ Unfortunately, SCD during dialysis may occur in the absence of typical ICD criteria, owing to complex interactions between hemodynamic, electrolytic, hypertrophic, and electrophysiologic factors, ${ }^{107}$ and further prospective studies are required before any specific recommendations can be made.

\section{SUMMARY}

Renal disease is a frequent partner of cardiovascular disease, whereby the presence of one accelerates the progression of the other. Moreover, renal disease adversely affects the efficacy and tolerability of a range of medical, interventional, and surgical interventions in CVD. Overall, however, the basic tenets of cardiovascular management remain unchanged by the presence of renal disease, no matter how advanced. Treatment priorities remain the early identification of risk factors, treatment and prevention of CKD and CVD where possible, and, where present, attenuation of the progression of both disease states. Moreover, clinicians should avoid the occurrence of acute kidney injury, through the use of drugs such as ACE-Is, or the minimization of hypotension, nephrotoxics, or contrast agents during invasive or surgical procedures. A key problem in the management of patients with CKD is the lack of prospective, randomized controlled trials. Data from such studies are sorely needed in a variety of areas such as the optimum strategy in patients with moderate and severe CKD and concomitant $\mathrm{CAD}, \mathrm{CHF}$, or AF. Therefore, more extensive study is required in this area of cardiovascular medicine to broaden the understanding of the underlying disease processes and to validate medical interventions from drugs through to surgery in the context of kidney impairment, thus ensuring optimal outcomes and preservation of quality of life in this challenging patient cohort.

\section{REFERENCES}

1. Keith DS, Nichols GA, Gullion CM, et al. Longitudinal follow-up and outcomes among a population with chronic kidney disease in a large managed care organization. Arch Intern Med 2004;164: 659-63.

2. Bakris GL, Ritz E. The message for world kidney day 2009: hypertension and kidney disease: a marriage that should be prevented. Kidney Int 2009; 75:449-52.

3. Maioli M, Toso A, Leoncini M, et al. Persistent renal damage after contrast-induced acute kidney injury: incidence, evolution, risk factors, and prognosis. Circulation 2012;125:3099-107.
4. Shepherd J, Kastelein JJ, Bittner V, et al. Intensive lipid lowering with atorvastatin in patients with coronary heart disease and chronic kidney disease: the TNT (treating to new targets) study. J Am Coll Cardiol 2008;51:1448-54.

5. Santopinto JJ, Fox KA, Goldberg RJ, et al. Creatinine clearance and adverse hospital outcomes in patients with acute coronary syndromes: findings from the global registry of acute coronary events (grace). Heart 2003;89:1003-8.

6. Damman K, Valente MA, Voors AA, et al. Renal impairment, worsening renal function, and outcome in patients with heart failure: an updated meta-analysis. Eur Heart J 2014;35:455-69.

7. Hohnloser SH, Hijazi Z, Thomas L, et al. Efficacy of apixaban when compared with warfarin in relation to renal function in patients with atrial fibrillation: insights from the ARISTOTLE trial. Eur Heart J 2012; 33:2821-30.

8. Poli D, Antonucci E, Zanazzi M, et al. Impact of glomerular filtration estimate on bleeding risk in very old patients treated with vitamin $\mathrm{k}$ antagonists. Results of EPICA study on the behalf of FCSA (Italian Federation of Anticoagulation Clinics). Thromb Haemost 2012;107:1100-6.

9. Ostchega Y, Yoon SS, Hughes J, et al. Hypertension awareness, treatment, and control—continued disparities in adults: United States, 2005-2006. NCHS Data Brief 2008;1-8.

10. Nichols M, Townsend $N$, Scarborough $P$, et al. Trends in age-specific coronary heart disease mortality in the European Union over three decades: 1980-2009. Eur Heart J 2013;34:3017-27.

11. Cerasola G, Cottone S, Mule G. The progressive pathway of microalbuminuria: from early marker of renal damage to strong cardiovascular risk predictor. J Hypertens 2010;28:2357-69.

12. Vanholder R, Massy Z, Argiles A, et al. Chronic kidney disease as cause of cardiovascular morbidity and mortality. Nephrol Dial Transplant 2005;20:1048-56.

13. Collins AJ, Li S, Gilbertson DT, et al. Chronic kidney disease and cardiovascular disease in the Medicare population. Kidney Int Suppl 2003;S24-31.

14. Gevaert SA, De Bacquer D, Evrard P, et al. Renal dysfunction in STEMI-patients undergoing primary angioplasty: higher prevalence but equal prognostic impact in female patients; an observational cohort study from the Belgian STEMI Registry. BMC Nephrol 2013;14:62.

15. Kanbay M, Goldsmith D, Akcay A, et al. Phosphate - the silent stealthy cardiorenal culprit in all stages of chronic kidney disease: a systematic review. Blood Purif 2009;27:220-30.

16. Cachofeiro V, Goicochea M, de Vinuesa SG, et al. Oxidative stress and inflammation, a link between chronic kidney disease and cardiovascular disease. Kidney Int Suppl 2008;S4-9. 
17. McCullough PA, Lepor NE. Piecing together the evidence on anemia: the link between chronic kidney disease and cardiovascular disease. Rev Cardiovasc Med 2005;6(Suppl 3):S4-12.

18. Shulman NB, Ford CE, Hall WD, et al. Prognostic value of serum creatinine and effect of treatment of hypertension on renal function. Results from the hypertension detection and follow-up program. The Hypertension Detection and Follow-Up Program Cooperative Group. Hypertension 1989;13:180-93.

19. Berl T, Henrich W. Kidney-heart interactions: epidemiology, pathogenesis, and treatment. Clin J Am Soc Nephrol 2006;1:8-18.

20. Luciano Ede P, Luconi PS, Sesso RC, et al. Prospective study of 2151 patients with chronic kidney disease under conservative treatment with multidisciplinary care in the Vale do Paraiba, SP. J Bras Nefrol 2012;34:226-34.

21. Szummer K, Lundman P, Jacobson SH, et al. Relation between renal function, presentation, use of therapies and in-hospital complications in acute coronary syndrome: data from the Swedeheart Register. J Intern Med 2010;268:40-9.

22. Thygesen K, Alpert JS, Jaffe AS, et al. Third universal definition of myocardial infarction. J Am Coll Cardiol 2012;60:1581-98.

23. End C, Seliger SL, Defilippi CR. Interpreting cardiac troponin results from highly sensitive assays in patients with chronic kidney disease: acute coronary syndromes and beyond. Coron Artery Dis 2013;24:720-3.

24. Ohtake T, Kobayashi S, Moriya H, et al. High prevalence of occult coronary artery stenosis in patients with chronic kidney disease at the initiation of renal replacement therapy: an angiographic examination. J Am Soc Nephrol 2005;16:1141-8.

25. Iliou MC, Fumeron $\mathrm{C}$, Benoit $\mathrm{MO}$, et al. Factors associated with increased serum levels of cardiac troponins T and I in chronic haemodialysis patients: Chronic Haemodialysis and New Cardiac Markers Evaluation (CHANCE) study. Nephrol Dial Transplant 2001;16:1452-8.

26. Komukai K, Ogawa T, Yagi H, et al. Renal insufficiency is related to painless myocardial infarction. Circ J 2007;71:1366-9.

27. Kramer H, Toto R, Peshock R, et al. Association between chronic kidney disease and coronary artery calcification: the Dallas Heart Study. J Am Soc Nephrol 2005; 16:507-13.

28. Cao XF, Yan LQ, Han LX, et al. Association of mild to moderate kidney dysfunction with coronary artery calcification in patients with suspected coronary artery disease. Cardiology 2011;120:211-6.

29. Budoff MJ, Rader DJ, Reilly MP, et al. Relationship of estimated GFR and coronary artery calcification in the CRIC (Chronic Renal Insufficiency Cohort) study. Am J Kidney Dis 2011;58:519-26.
30. Chiu YW, Adler SG, Budoff MJ, et al. Coronary artery calcification and mortality in diabetic patients with proteinuria. Kidney Int 2010;77:1107-14.

31. Russo D, Morrone L, Russo L. Coronary artery calcification and cardiovascular mortality in predialysis patients. Kidney Int 2011;79:258 [author reply: 258].

32. Karthikeyan V, Ananthasubramaniam K. Coronary risk assessment and management options in chronic kidney disease patients prior to kidney transplantation. Curr Cardiol Rev 2009;5:177-86.

33. Hansson L, Zanchetti A, Carruthers SG, et al. Effects of intensive blood-pressure lowering and low-dose aspirin in patients with hypertension: principal results of the Hypertension Optimal Treatment (HOT) randomised trial. HOT Study Group. Lancet 1998;351:1755-62.

34. Jardine MJ, Ninomiya T, Perkovic V, et al. Aspirin is beneficial in hypertensive patients with chronic kidney disease: a post-hoc subgroup analysis of a randomized controlled trial. J Am Coll Cardiol 2010;56:956-65.

35. Rosendorff C. Hypertension and coronary artery disease: a summary of the American Heart Association scientific statement. J Clin Hypertens (Greenwich) 2007:9:790-5.

36. Baigent $\mathrm{C}$, Landray MJ, Reith $\mathrm{C}$, et al. The effects of lowering LDL cholesterol with simvastatin plus ezetimibe in patients with chronic kidney disease (Study of Heart and Renal Protection): a randomised placebo-controlled trial. Lancet 2011;377: 2181-92.

37. Wanner C, Krane V, Marz W, et al. Atorvastatin in patients with type 2 diabetes mellitus undergoing hemodialysis. N Engl J Med 2005;353:238-48.

38. Hamm CW, Bassand JP, Agewall S, et al. ESC guidelines for the management of acute coronary syndromes in patients presenting without persistent ST-segment elevation: the Task Force for the Management of Acute Coronary Syndromes (ACS) in patients presenting without persistent ST-segment elevation of the European Society of Cardiology (ESC). Eur Heart J 2011;32:2999-3054.

39. Moscucci M, Fox KA, Cannon CP, et al. Predictors of major bleeding in acute coronary syndromes: the Global Registry of Acute Coronary Events (GRACE). Eur Heart J 2003;24:1815-23.

40. Sedlis SP, Jurkovitz CT, Hartigan PM, et al. Optimal medical therapy with or without percutaneous coronary intervention for patients with stable coronary artery disease and chronic kidney disease. Am J Cardiol 2009; 104:1647-53.

41. Sedlis SP, Jurkovitz CT, Hartigan PM, et al. Health status and quality of life in patients with stable coronary artery disease and chronic kidney disease treated with optimal medical therapy or percutaneous coronary intervention (post hoc findings 
from the COURAGE trial). Am J Cardiol 2013;112: 1703-8.

42. Reed M, Meier P, Tamhane UU, et al. The relative renal safety of iodixanol compared with lowosmolar contrast media: a meta-analysis of randomized controlled trials. JACC Cardiovasc Interv 2009;2:645-54.

43. Hecker PA, Leopold JA, Gupte SA, et al. Impact of glucose-6-phosphate dehydrogenase deficiency on the pathophysiology of cardiovascular disease. Am J Physiol Heart Circ Physiol 2013;304:H491-500.

44. Leoncini M, Toso A, Maioli M, et al. Early high-dose rosuvastatin for contrast-induced nephropathy prevention in acute coronary syndrome. Results from Protective Effect of Rosuvastatin and Antiplatelet Therapy on Contrast-Induced Acute Kidney Injury and Myocardial Damage in Patients with Acute Coronary Syndrome (PRATO-ACS study). J Am Coll Cardiol 2013;63:71-9.

45. Hoshi T, Sato A, Kakefuda Y, et al. Preventive effect of statin pretreatment on contrast-induced acute kidney injury in patients undergoing coronary angioplasty: propensity score analysis from a multicenter registry. Int J Cardiol 2014;171:243-9.

46. Er F, Nia AM, Dopp H, et al. Ischemic preconditioning for prevention of contrast medium-induced nephropathy: randomized pilot RENPRO trial (renal protection trial). Circulation 2012;126:296-303.

47. Deftereos S, Giannopoulos G, Tzalamouras V, et al. Renoprotective effect of remote ischemic postconditioning by intermittent balloon inflations in patients undergoing percutaneous coronary intervention. J Am Coll Cardiol 2013;61:1949-55.

48. Huang TM, Wu VC, Young GH, et al. Preoperative proteinuria predicts adverse renal outcomes after coronary artery bypass grafting. J Am Soc Nephrol 2011;22:156-63.

49. Winkelmayer WC, Levin R, Avorn J. Chronic kidney disease as a risk factor for bleeding complications after coronary artery bypass surgery. Am J Kidney Dis 2003;41:84-9.

50. Chang TI, Leong TK, Kazi DS, et al. Comparative effectiveness of coronary artery bypass grafting and percutaneous coronary intervention for multivessel coronary disease in a community-based population with chronic kidney disease. Am Heart J 2013;165:800-8, 808.e1-2.

51. Weintraub WS, Grau-Sepulveda MV, Weiss JM, et al. Comparative effectiveness of revascularization strategies. N Engl J Med 2012;366:1467-76.

52. Chawla LS, Zhao Y, Lough FC, et al. Off-pump versus on-pump coronary artery bypass grafting outcomes stratified by preoperative renal function. J Am Soc Nephrol 2012;23:1389-97.

53. Umana E, Ahmed W, Alpert MA. Valvular and perivalvular abnormalities in end-stage renal disease. Am J Med Sci 2003;325:237-42.
54. Benjamin EJ, Levy D, Vaziri SM, et al. Independent risk factors for atrial fibrillation in a populationbased cohort. The Framingham Heart Study. JAMA 1994;271:840-4.

55. Cerasola G, Nardi E, Palermo A, et al. Epidemiology and pathophysiology of left ventricular abnormalities in chronic kidney disease: a review. J Nephrol 2011;24:1-10.

56. Wachtell K, Devereux RB, Lyle PA, et al. The left atrium, atrial fibrillation, and the risk of stroke in hypertensive patients with left ventricular hypertrophy. Ther Adv Cardiovasc Dis 2008;2:507-13.

57. Soliman EZ, Prineas RJ, Go AS, et al. Chronic kidney disease and prevalent atrial fibrillation: the Chronic Renal Insufficiency Cohort (CRIC). Am Heart J 2010;159:1102-7.

58. Prineas RJ, Soliman EZ, Howard G, et al. The sensitivity of the method used to detect atrial fibrillation in population studies affects group-specific prevalence estimates: ethnic and regional distribution of atrial fibrillation in the regards study. J Epidemiol 2009;19:177-81.

59. Korantzopoulos P, Liu T, Letsas KP, et al. The epidemiology of atrial fibrillation in end-stage renal disease. J Nephrol 2013;26:617-23.

60. Chan KE, Lazarus JM, Hakim RM. Digoxin associates with mortality in ESRD. J Am Soc Nephrol 2010;21:1550-9.

61. Nimmo C, Wright M, Goldsmith D. Management of atrial fibrillation in chronic kidney disease: double trouble. Am Heart J 2013;166:230-9.

62. Berkowitsch A, Kuniss M, Greiss H, et al. Impact of impaired renal function and metabolic syndrome on the recurrence of atrial fibrillation after catheter ablation: a long term follow-up. Pacing Clin Electrophysiol 2012;35:532-43.

63. Naruse $\mathrm{Y}$, Tada $\mathrm{H}$, Sekiguchi $\mathrm{Y}$, et al. Concomitant chronic kidney disease increases the recurrence of atrial fibrillation after catheter ablation of atrial fibrillation: a mid-term follow-up. Heart Rhythm 2011;8:335-41.

64. Tokuda M, Yamane T, Matsuo S, et al. Relationship between renal function and the risk of recurrent atrial fibrillation following catheter ablation. Heart 2011;97:137-42.

65. Lip GY, Nieuwlaat R, Pisters R, et al. Refining clinical risk stratification for predicting stroke and thromboembolism in atrial fibrillation using a novel risk factor-based approach: the Euro Heart Survey on Atrial Fibrillation. Chest 2010;137:263-72.

66. Roldan V, Marin F, Manzano-Fernandez S, et al. Does chronic kidney disease improve the predictive value of the CHADS2 and CHA2DS2-VASC stroke stratification risk scores for atrial fibrillation? Thromb Haemost 2013;109:956-60.

67. Go AS, Fang MC, Udaltsova N, et al. Impact of proteinuria and glomerular filtration rate on risk of 
thromboembolism in atrial fibrillation: the Anticoagulation and Risk Factors in Atrial Fibrillation (ATRIA) study. Circulation 2009;119:1363-9.

68. Nakagawa K, Hirai T, Takashima S, et al. Chronic kidney disease and CHADS(2) score independently predict cardiovascular events and mortality in patients with nonvalvular atrial fibrillation. Am J Cardiol 2011;107:912-6.

69. Olesen JB, Lip GY, Kamper AL, et al. Stroke and bleeding in atrial fibrillation with chronic kidney disease. N Engl J Med 2012;367:625-35.

70. Pisters R, Lane DA, Nieuwlaat R, et al. A novel userfriendly score (has-bled) to assess 1-year risk of major bleeding in patients with atrial fibrillation: The Euro Heart Survey. Chest 2010;138:1093-100.

71. Limdi NA, Limdi MA, Cavallari L, et al. Warfarin dosing in patients with impaired kidney function. Am J Kidney Dis 2010;56:823-31.

72. Chan KE, Lazarus JM, Thadhani R, et al. Warfarin use associates with increased risk for stroke in hemodialysis patients with atrial fibrillation. J Am Soc Nephrol 2009;20:2223-33.

73. Winkelmayer WC, Liu J, Setoguchi S, et al. Effectiveness and safety of warfarin initiation in older hemodialysis patients with incident atrial fibrillation. Clin J Am Soc Nephrol 2011;6:2662-8.

74. Lai HM, Aronow WS, Kalen P, et al. Incidence of thromboembolic stroke and of major bleeding in patients with atrial fibrillation and chronic kidney disease treated with and without warfarin. Int $\mathrm{J}$ Nephrol Renovasc Dis 2009;2:33-7.

75. Knoll F, Sturm G, Lamina C, et al. Coumarins and survival in incident dialysis patients. Nephrol Dial Transplant 2012;27:332-7.

76. Connolly SJ, Ezekowitz MD, Yusuf S, et al. Dabigatran versus warfarin in patients with atrial fibrillation. N Engl J Med 2009;361:1139-51.

77. Granger CB, Alexander JH, McMurray JJ, et al. Apixaban versus warfarin in patients with atrial fibrillation. N Engl J Med 2011;365:981-92.

78. Patel MR, Mahaffey KW, Garg J, et al. Rivaroxaban versus warfarin in nonvalvular atrial fibrillation. N Engl J Med 2011;365:883-91.

79. Damman K, Navis G, Smilde TD, et al. Decreased cardiac output, venous congestion and the association with renal impairment in patients with cardiac dysfunction. Eur J Heart Fail 2007;9:872-8.

80. Brown JR, Uber PA, Mehra MR. The progressive cardiorenal syndrome in heart failure: Mechanisms and therapeutic insights. Curr Treat Options Cardiovasc Med 2008; 10:342-8.

81. Erdmann $E$, Lechat $P$, Verkenne $P$, et al. Results from post-hoc analyses of the CIBIS II trial: effect of bisoprolol in high-risk patient groups with chronic heart failure. Eur J Heart Fail 2001;3:469-79.

82. Ghali JK, Wikstrand J, Van Veldhuisen DJ, et al. The influence of renal function on clinical outcome and response to beta-blockade in systolic heart failure: insights from Metoprolol CR/XL Randomized Intervention Trial in Chronic HF (MERIT-HF). J Card Fail 2009;15:310-8.

83. Bakris GL, Hart P, Ritz E. Beta blockers in the management of chronic kidney disease. Kidney Int 2006:70:1905-13.

84. Sarafidis PA, Ruilope LM. Aggressive blood pressure reduction and renin-angiotensin system blockade in chronic kidney disease: time for reevaluation? Kidney Int 2013;85:536-46.

85. Molnar MZ, Kalantar-Zadeh K, Lott EH, et al. ACE inhibitor and angiotensin receptor blocker use and mortality in patients with chronic kidney disease. J Am Coll Cardiol 2013.

86. Ljungman S, Kjekshus J, Swedberg K. Renal function in severe congestive heart failure during treatment with enalapril (the Cooperative North Scandinavian Enalapril Survival Study [Consensus] Trial). Am J Cardiol 1992;70:479-87.

87. Swedberg K, Eneroth P, Kjekshus J, et al. Effects of enalapril and neuroendocrine activation on prognosis in severe congestive heart failure (follow-up of the Consensus Trial). Consensus Trial Study Group. Am J Cardiol 1990;66:40D-4D [discussion: 44D-45D].

88. Bowling CB, Sanders PW, Allman RM, et al. Effects of enalapril in systolic heart failure patients with and without chronic kidney disease: insights from the SOLVD treatment trial. Int J Cardiol 2013;167: 151-6.

89. Konstam MA, Neaton JD, Dickstein K, et al. Effects of high-dose versus low-dose losartan on clinical outcomes in patients with heart failure (HEAAL study): a randomised, double-blind trial. Lancet 2009;374:1840-8.

90. Pitt B, Zannad F, Remme WJ, et al. The effect of spironolactone on morbidity and mortality in patients with severe heart failure. Randomized Aldactone Evaluation Study Investigators. N Engl J Med 1999;341:709-17.

91. Zannad F, McMurray JJ, Krum H, et al. Eplerenone in patients with systolic heart failure and mild symptoms. N Engl J Med 2011;364:11-21.

92. Vardeny $\mathrm{O}, \mathrm{Wu} \mathrm{DH}$, Desai A, et al, RALES Investigators. Influence of baseline and worsening renal function on efficacy of spironolactone in patients with severe heart failure: insights from RALES (Randomized Aldactone Evaluation Study). J Am Coll Cardiol 2012;60:2082-9.

93. McMurray JJ, Adamopoulos S, Anker SD, et al, Task Force for the Diagnosis and Treatment of Acute and Chronic Heart Failure of the European Society of Cardiology, Guidelines ESC Committee for Practice. ESC guidelines for the diagnosis and treatment of acute and chronic heart failure 2012: the Task Force for the Diagnosis and Treatment of 
Acute and Chronic Heart Failure 2012 of the European Society of Cardiology. Developed in collaboration with the Heart Failure Association (HFA) of the ESC. Eur J Heart Fail 2012;14:803-69.

94. Eshaghian S, Horwich TB, Fonarow GC. Relation of loop diuretic dose to mortality in advanced heart failure. Am J Cardiol 2006;97:1759-64.

95. Wollam GL, Tarazi RC, Bravo EL, et al. Diuretic potency of combined hydrochlorothiazide and furosemide therapy in patients with azotemia. Am J Med 1982;72:929-38.

96. Tang WH, Tong W, Jain A, et al. Evaluation and longterm prognosis of new-onset, transient, and persistent anemia in ambulatory patients with chronic heart failure. J Am Coll Cardiol 2008;51:569-76.

97. Kosiborod M, Smith GL, Radford MJ, et al. The prognostic importance of anemia in patients with heart failure. Am J Med 2003;114:112-9.

98. Al-Ahmad A, Rand WM, Manjunath G, et al. Reduced kidney function and anemia as risk factors for mortality in patients with left ventricular dysfunction. J Am Coll Cardiol 2001;38:955-62.

99. Palmer SC, Navaneethan SD, Craig JC, et al. Metaanalysis: erythropoiesis-stimulating agents in patients with chronic kidney disease. Ann Intern Med 2010;153:23-33.

100. Jing Z, Wei-jie $Y$, Nan Z, et al. Hemoglobin targets for chronic kidney disease patients with anemia: a systematic review and meta-analysis. PLoS One 2012; 7:e43655.

101. Cleland JG, Daubert JC, Erdmann E, et al, Committee $\mathrm{C}-\mathrm{H}$ study Steering Investigators. The CARE-HF study (Cardiac Resynchronisation in Heart Failure study): rationale, design and end-points. Eur J Heart Fail 2001;3:481-9.

102. Boerrigter G, Costello-Boerrigter LC, Abraham WT, et al. Cardiac resynchronization therapy improves renal function in human heart failure with reduced glomerular filtration rate. J Card Fail 2008;14:539-46.

103. Bansal N, Tighiouart F, Weiner D, et al. Anemia as a risk factor for kidney function decline in individuals with heart failure. Am J Cardiol 2007;99:1137-42.

104. Spittell PC, Hayes DL. Venous complications after insertion of a transvenous pacemaker. Mayo Clin Proc 1992;67:258-65.

105. Herzog CA, Li S, Weinhandl ED, et al. Survival of dialysis patients after cardiac arrest and the impact of implantable cardioverter defibrillators. Kidney Int 2005;68:818-25.

106. Khan F, Adelstein E, Saba S. Implantable cardioverter defibrillators confer survival benefit in patients with renal insufficiency but not in dialysisdependent patients. J Interv Card Electrophysiol 2010;28:117-23.

107. Green D, Roberts PR, New DI, et al. Sudden cardiac death in hemodialysis patients: an in-depth review. Am J Kidney Dis 2011;57:921-9.
108. U.S. Renal Data System. USRDS 2013 annual data report: atlas of chronic kidney disease and endstage renal disease in the United States. 2013. p. 1, 2. Q13

109. Effect of enalapril on survival in patients with reduced left ventricular ejection fractions and congestive heart failure. The SOLVD investigators. N Engl J Med 1991;325:293-302.

110. McMurray JJ, Ostergren J, Swedberg K, et al, $\mathrm{CHARM}$ Investigators and Committees. Effects of candesartan in patients with chronic heart failure and reduced left-ventricular systolic function taking angiotensin-converting-enzyme inhibitors: the CHARM-added trial. Lancet 2003;362:767-71.

111. Cleland JG, Daubert JC, Erdmann E, et al. Cardiac Resynchronization-Heart Failure Study I. The effect of cardiac resynchronization on morbidity and mortality in heart failure. N Engl J Med 2005;352: 1539-49.

112. Effects of enalapril on mortality in severe congestive heart failure. Results of the Cooperative North Scandinavian Enalapril Survival Study (Consensus). The Consensus Trial Study Group. N Engl J Med 1987;316:1429-35.

113. Effect of metoprolol $\mathrm{CR} / \mathrm{XL}$ in chronic heart failure: metoprolol $\mathrm{CR} / \mathrm{XL}$ randomised intervention trial in congestive heart failure (MERIT-HF). Lancet 1999; 353:2001-7.

114. The Cardiac Insufficiency Bisoprolol Study II (CIBIS-II): a randomised trial. Lancet 1999;353:9-13.

115. Packer M, Coats AJ, Fowler MB, et al, Carvedilol Prospective Randomized Cumulative Survival Study Group. Effect of carvedilol on survival in severe chronic heart failure. N Engl J Med 2001;344:1651-8.

116. Dargie HJ. Effect of carvedilol on outcome after myocardial infarction in patients with leftventricular dysfunction: the Capricorn randomised trial. Lancet 2001;357:1385-90.

117. Digitalis Investigation Group. The effect of digoxin on mortality and morbidity in patients with heart failure. N Engl J Med 1997;336:525-33.

118. Swedberg K, Komajda M, Bohm M, et al, SHIFT Investigators. Ivabradine and outcomes in chronic heart failure (SHIFT): a randomised placebocontrolled study. Lancet 2010;376:875-85.

119. Taylor AL, Ziesche S, Yancy C, et al, African-American Heart Failure Trial Investigators. Combination of isosorbide dinitrate and hydralazine in blacks with heart failure. N Engl J Med 2004;351:2049-57.

120. Moss AJ, Zareba W, Hall WJ, et al, Multicenter Automatic Defibrillator Implantation Trial II Investigators. Prophylactic implantation of a defibrillator in patients with myocardial infarction and reduced ejection fraction. N Engl J Med 2002;346:877-83.

121. Moss AJ, Hall WJ, Cannom DS, et al. Cardiacresynchronization therapy for the prevention of heart-failure events. N Engl J Med 2009;361: 1329-38. 


\section{AUTHOR QUERY FORM}

\begin{tabular}{|c|c|}
\hline 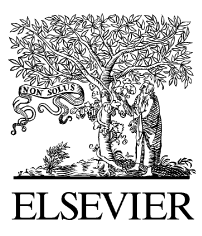 & $\begin{array}{l}\text { Journal: ICCL } \\
\text { Article Number: } 137\end{array}$ \\
\hline
\end{tabular}

Dear Author,

Please check your proof carefully and mark all corrections at the appropriate place in the proof (e.g., by using on-screen annotation in the PDF file) or compile them in a separate list. Note: if you opt to annotate the file with software other than Adobe Reader then please also highlight the appropriate place in the PDF file. To ensure fast publication of your paper please return your corrections within 48 hours.

For correction or revision of any artwork, please consult http://www.elsevier.com/artworkinstructions.

Any queries or remarks that have arisen during the processing of your manuscript are listed below and highlighted by flags in the proof.

\begin{tabular}{|c|l|}
\hline $\begin{array}{c}\text { Location } \\
\text { in article }\end{array}$ & \multicolumn{1}{c|}{$\begin{array}{c}\text { Query / Remark: Click on the Q link to find the query's location in text } \\
\text { Please insert your reply or correction at the corresponding line in the proof }\end{array}$} \\
\hline Q1 & $\begin{array}{l}\text { Please approve the short title to be used in the running head at the top of each right-hand page. } \\
\text { This is how your name will appear on the contributor's list. Please add your academic title and any other } \\
\text { necessary titles and professional affiliations, verify the information, and OK } \\
\text { ROGER REAR, The Heart Hospital, University College Hospitals NHS Trust; The Hatter Cardiovascular } \\
\text { Institute, University College London, London, United Kingdom } \\
\text { PASCAL MEIER, The Heart Hospital, University College Hospitals NHS Trust, London, United } \\
\text { Kingdom } \\
\text { ROBERT M. BELL, The Heart Hospital, University College Hospitals NHS Trust; The Hatter } \\
\text { Cardiovascular Institute, University College London, London, United Kingdom }\end{array}$ \\
Q3 & $\begin{array}{l}\text { Are author names and order of authors OK as set? } \\
\text { Please provide professional degrees for all the authors. } \\
\text { Q5 }\end{array}$ \\
$\begin{array}{l}\text { The following synopsis is the one that you supplied, but edited down to fewer than 100 words. Please } \\
\text { confirm OK, or submit a replacement (also less than 100 words). Please note that the synopsis will appear in } \\
\text { PubMed: Traditional cardiovascular risk factors, particularly hypertension and diabetes, are common in the } \\
\text { disease processes of both renal and cardiac pathology. Unfortunately the coexistence of renal impairment is } \\
\text { not an innocent bystander in cardiovascular disease; the addition to cardiac disorder of involvement of } \\
\text { a second organ system not only increases the prevalence and severity of cardiovascular disease, it also } \\
\text { negatively affects prognostic outcomes and the safety and efficacy of cardiac interventions. This article } \\
\text { discusses the role and impact of kidney disease in the cardiac patient in 3 key common cardiovascular } \\
\text { processes: coronary artery disease, arrhythmia, and heart failure. } \\
\text { Please verify the affiliation addresses and provide the missing information (department name for both } \\
\text { affiliations). And please indicate (or confirm) which address is the preferred one for correspondence. }\end{array}$ \\
\hline
\end{tabular}




\begin{tabular}{|l|l|} 
Q7 & $\begin{array}{l}\text { As per the editorial remarks, "Please check disclosure statement and change as necessary. Statement was } \\
\text { composed by Publisher." } \\
\text { If there are any drug dosages in your article, please verify them and indicate that you have done so by } \\
\text { initialing this query. } \\
\text { Please provide the volume number. } \\
\text { Q10 }\end{array}$ \\
Q11 & $\begin{array}{l}\text { Please provide the volume number. } \\
\text { Please provide the volume number. } \\
\text { Q12 }\end{array}$ \\
Q13 & $\begin{array}{l}\text { Please provide the volume number and page range. } \\
\text { As per the editorial remarks, "Please check the table caption and change as necessary. Caption was added } \\
\text { by publisher." } \\
\text { The designators "a \& b" are present in Table. Please specify in a footnote what they indicate. }\end{array}$ \\
Q15 & $\begin{array}{l}\text { Please check this box or indicate } \\
\text { your approval if you have no } \\
\text { corrections to make to the PDF file }\end{array}$ \\
\hline
\end{tabular}

Thank you for your assistance. 